\title{
Pemilihan Prioritas Service terhadap Development Perusahaan Kategori Kecil dan Menengah dari Lembaga Pengembangan Bisnis
}

\author{
Ba'da Maulidia Rizqi Ba'da Putri, Imam Baihaqi, dan Satria Fadil Persada \\ Departemen Manajemen Bisnis, Institut Teknologi Sepuluh Nopember (ITS) \\ e-mail: ibaihaqi@mb.its.ac.id
}

\begin{abstract}
Abstrak - Salah satu aspek penting dalam tingkat ekonomi suatu negara adalah UKM, dimana UKM telah berkontribusi pada penyerapan tenaga kerja dan produk domestik bruto. Tapi walaupun demikian, UKM juga mengalami kegagalan dengan angka yang cukup tinggi. Oleh karena itu program pengembangan bagi usaha kecil dan menengah diperlukan agar dapat mengurangi tingkat kegagalan dari UKM. Beberapa dukungan yang telah diberikan oleh pemerintah untuk mendorong ketahanan dan pertumbuhan UKM adalah melalui Peraturan Presiden Nomor 27 Tahun 2013 tentang Pengembangan Inkubator Wirausaha serta Peraturan Menteri Negara Koperasi dan UKM Republik Indonesia Nomor 02 Tahun 2008 tentang Pengembangan Business Development Service-Provider (BDS-P). Pada prakteknya, penyusunan layanan pengembangan bisnis bagi UKM didasarkan atas ketentuan dari lembaga pengembangan bisnis terkait. Penyusan layanan tidak didasarkan atas permintaan atau kebutuhan dari UKM sebagai tenant. Padahal kesuksesan inkubator bisnis dan BDS-P bergantung pada kesesuaian layanan yang diberikan dengan kebutuhan dari UKM. Penelitian ini bertujuan untuk menentukan prioritas layanan yang dapat berdampak pada pengembangan UKM dari berbagai lembaga pengembangan bisnis, baik inkubator bisnis maupun BDS-P, dimana penelitian ini mengambil studi kasus UKM di Surabaya dengan berbagai sektor ekonomi. Pemilihan studi kasus UKM di Surabaya dikarenakan perekonomian Surabaya bergantung pada UKM, sehingga Surabaya memberikan perhatian besar pada pertumbuhan UKM. Untuk mencapai tujuan penelitian, penelitian ini menggunakan metode Delphi dan metode AHP. Hasil penyaringan aspirasi layanan menggunakan metode Delphi menunjukkan bahwa terdapat 9 kategori dan 52 sub layanan untuk mengembangkan UKM. Hasil pembobotan perbandingan berpasangan AHP menghasilkan 5 prioritas kategori layanan yang meliputi pendampingan oleh pakar, akses jaringan usaha, layanan pendukung, akses pendanaan, serta bantuan riset.
\end{abstract}

Kata Kunci-Analytic Hierarchy Process, Business Development Service Provider, Inkubator Bisnis, Metode Delphi, UKM

\section{PENDAHULUAN}

$\mathrm{U}$ KM (Usaha Kecil dan Menengah) menjadi bagian integral dari ekonomi bisnis Indonesia, yang mempunyai peranan, potensi, serta kedudukan sangat penting dan strategis dalam mewujudkan struktur perekonomian nasional berdasarkan demokrasi ekonomi [1]. UKM telah berkontribusi pada Produk Domestik Bruto (PDB) dan penyerapan tenaga kerja nasional. Berdasarkan data Kementerian Koperasi dan UKM [2], apabila dibandingkan dengan kontribusi Usaha Besar (UB), UKM menyumbang sekitar 60\% PDB nasional meliputi PDB atas Dasar Harga Berlaku dan Harga Konstan 2000 serta menyumbang 90\% penyerapan tenaga kerja nasional. Kontribusi yang besar dari UKM membuktikan bahwa kewirausahaan melalui UKM merupakan aspek penting bagi perekonomian suatu negara.

Namun, walaupun kewirausahaan merupakan hal yang penting dalam pertumbuhan ekonomi suatu negara [3], dilain sisi UKM juga memiliki tingkat kegagalan yang cukup signifikan [4]. Di Indonesia sendiri tingkat kegagalan usaha kecil telah mencapai angka 78\%, dimana $80 \%$ diantaranya telah gagal dalam kurun waktu 5 tahun pertama [5]. Kegagalan UKM di Indonesia disebabkan oleh berbagai permasalahan terkait keuangan [6], informasi teknik dan pelatihan, kontrol kualitas, manajemen, fasilitas produksi [7], dimana 80\% tingkat kegagalan UKM di Indonesia disebabkan oleh kurang adanya pendampingan dari pakar [8] Mengingat pentingnya UKM bagi perekonomian nasional, pemberdayaan UKM perlu untuk dilakukan agar dapat mengurangi tingkat kegagalan serta dapat memicu pertumbuhan ekonomi nasional dan pembangunan yang berkelanjutan.

Pemerintah telah memberikan dukungan kepada UKM melalui berbagai cara meliputi Rencana Pembangunan Jangka Menengah Nasional Tahun 2015-2019, Peraturan Presiden Nomor 27 Tahun 2013 tentang Pengembangan Inkubator Wirausaha, dan Peraturan Menteri Negara Koperasi dan UKM Republik Indonesia Nomor 02 Tahun 2008 tentang Pemberdayaan Business Development Service Provider (BDS-P) untuk pengembangan Koperasi dan UMKM (KUMKM).

Berdasarkan Perpres Nomor 27 Tahun 2013, inkubator wirausaha adalah suatu lembaga intermediasi yang melakukan proses inkubasi terhadap peserta inkubasi (tenant, klien inkubator, atau inkubati) dan memiliki bangunan fisik untuk ruang usaha sehari-hari bagi peserta inkubasi. Dalam proses inkubasi oleh inkubator bisnis, terdapat beberapa layanan yang diberikan kepada perusahaan tenant diantaranya ruang kerja bersama yang layak [11] beserta peralatan, pelayanan konsep penciptaan bisnis start-up, jasa pemasaran dan penjualan [12], layanan pendukung seperti perencanaan bisnis, sumber daya manusia [13], berbagai akses jaringan usaha, akses pendanaan, serta dukungan pengembangan kewirausaan dalam bentuk pelatihan, coaching, dan mentoring [14].

Sedangkan berdasarkan Peraturan Menteri Negara Koperasi dan UKM Republik Indonesia Nomor 02 Tahun 2008, business development service adalah kegiatan pemberian layanan pengembangan bisnis, untuk meningkatkan kinerja KUMKM, dimana BDS-P merupakan lembaga yang melakukan kegiatan business development service. Layanan yang diberikan oleh BDS-P kepada usaha kecil menengah meliputi kegiatan layanan informasi, pelatihan, konsultasi, penyelenggaraan kontrak bisnis, 
pendampingan pada seluruh aspek manajemen UKM [15], serta fasilitas untuk memperluas pasar dan memperoleh pendanaan dari berbagai lembaga [16]. Namun berdasarkan Peraturan Menteri Negara Koperasi dan UKM Republik Indonesia Nomor 02 Tahun 2008, layanan yang disediakan oleh BDS-P menyesuaikan kebutuhan UKM.

Melalui berbagai pelayanan yang diberikan oleh lembaga pengembangan bisnis baik inkubator bisnis maupun BDS-P, program pengembangan UKM dapat memberikan dukungan untuk meningkatkan tingkat ketahanan serta mempercepat perkembangan perusahaan [17]. Sehingga kesuksesan dari kedua lembaga pengembangan bisnis tersebut merupakan hal yang penting. Bergek dan Norman [18] menyatakan bahwa keberhasilan sebuah inkubator berkaitan dengan sejauh mana penyusunan layanan inkubator mampu memenuhi tujuan dari tenant. Begitu pula dengan BDS-P, keberhasilan program pengembangan UKM melalui BDS-P juga bergantung pada kesesuaian layanan yang disediakan oleh BDS-P dengan kebutuhan UKM. Sehingga, walaupun lembaga pengembangan bisnis mampu memberikan berbagai pelayanan kepada tenant, lembaga pengembangan bisnis perlu mengetahui dan memahami sudut pandang dari UKM sebagai tenant terkait layanan yang diperlukan untuk pengembangan UKM.

Di Indonesia, pelayanan yang diberikan oleh inkubator bisnis telah diatur dalam Peraturan Presiden Nomor 27 Tahun 2013 tentang Pengembangan Inkubator Wirausaha, sedangkan layanan yang disediakan oleh BDS-P menyesuaikan kebutuhan dari UKM. Pada kenyataannya, penyusunan layanan pengembangan UKM pada lembaga pengembangan bisnis ditetapkan secara langsung oleh lembaga atau tanpa menyaring aspirasi dari tenant $[6,19,20]$. Padahal untuk dapat mencapai kesuksesan dalam penerapan inkubator bisnis di Indonesia, inkubator bisnis perlu untuk mengetahui layanan apa yang diperlukan oleh UKM dari lembaga pengembangan bisnis untuk berkembang.

Oleh karena itu, penelitian ini bertujuan untuk mengidentifikasi prioritas layanan yang diperlukan oleh UKM pada lembaga pengembangan bisnis dengan studi kasus UKM di Surabaya. Pemilihan studi kasus UKM di Surabaya dikarenakan Surabaya merupakan salah satu kota di Indonesia yang menaruh perhatian besar pada perkembangan UKM. Hal tersebut dikarenakan $98 \%$ pembangunan ekonomi daerah kota Surabaya bergantung pada UKM [21]. Selain itu, sebagai kota ke 6 dengan jumlah UMKM terbanyak di Jawa Timur yaitu 260762-unit dan sebagai kota dengan populasi terbesar kedua di Indonesia, Surabaya turut memberikan kontribusi yang besar bagi perekonomian nasional. Tercatat menurut Dinas Koperasi UKM Jatim [22], UMKM di Surabaya terbukti telah menyerap tenaga kerja hingga 446.779 tenaga kerja.

\section{METODE PENELITIAN}

Dalam penelitian ini dilakukan tahap identifikasi layanan untuk pengembangan UKM dan pembobotan layanan pengembangan UKM pada lembaga pengembangan bisnis untuk menentukan prioritas layanan. Langkah pertama penelitian ini adalah identifikasi layanan pengembangan UKM yang dilakukan dengan metode Delphi yang terdiri atas 3 putaran. Putaran pertama adalah generative round yang dilakukan melalui wawancara mendalam dengan teknik laddering kepada 5 pemilik UKM di Surabaya. Terdapat 2 pertanyaan acuan yang digunakan dalam tahap generative round:

Pertanyaan 1 : "Permasalahan atau kendala apakah yang dihadapi oleh UKM?”

Pertanyaan 2 : "Pelayanan atau bantuan apakah yang diperlukan untuk membantu UKM dalam menghadapi permasalahan tersebut?"

Pada generative round, hasil data berupa transkip wawancara akan dianalisis menggunakan analisis konten yang diawali dengan kondensasi makna unit, pengkodean, dan pengelompokan kode kedalam kategori tertentu. Berdasarkan hasil analisis konten tersebut, disusun kuesioner yang akan digunakan dalam tahap pengumpulan data pada putaran kedua Delphi.

Selanjutnya, putaran kedua Delphi dilakukan dengan penyebaran kuesioner skala likert 5 poin dengan arti dari sangat tidak setuju hingga sangat setuju yang bertujuan untuk mengidentifikasi pencapaian konsensus dari kelima panelis. Penentuan ketercapaian konsensus didasarkan atas hasil pengolahan data statistik yang meliputi nilai median dan Interquartile Range (IQR). Konsensus telah tercapai apabila nilai median $\geq 4$ dan IQR $\leq 1$ [23]. Nilai median lebih dari sama dengan 4 menunjukkan bahwa penilaian pakar adalah setuju atau sangat setuju terhadap pernyataan. Sedangkan nilai IQR kurang dari sama dengan 1 menunjukkan persebaran data penilaian dari setiap pernyataan terpusat atau tidak bervariasi.

Apabila hasil pengolahan data putaran kedua Delphi tidak mencapai batas ketercapaian konsensus, maka dilakukan putaran ketiga Delphi dimana panelis memiliki kesempatan untuk memberikan pembenaran akan penilaiannya pada putaran kedua Delphi. Pelaksanaan tiga putaran survei pada metode Delphi dianggap telah cukup untuk mencapai konsensus [24] sehingga pada akhir putaran ketiga, layanan yang tidak mencapai konsensus akan dieliminasi dari daftar layanan pengembangan UKM.

Selanjutnya, setelah diperoleh daftar layanan pengembangan UKM, maka dilakukan pembobotan dengan metode Analytic Hierarchy Process (AHP) yang diawali dengan penyebaran kuesioner perbandingan berpasangan kepada 8 responden ahli yang meliputi 5 pemilik UKM, 2 orang pakar praktisi, dan 1 orang pakar akademisi. Setelah dilakukan penilaian perbandingan berpasangan, data kemudian diolah menggunakan aplikasi Expert Choice. Hasil pembobotan dari pengolahan aplikasi Expert Choice akan menunjukkan tingkat kepentingan antar layanan pengembangan UKM.

\section{ANALISIS DAN DISKUSI}

\section{A. Penentuan Panelis pada Metode Delphi}

Panelis pada metode Delphi terdiri atas 5 responden ahli dari UKM dengan memperhatikan beberapa kriteria UKM yaitu klasifikasi UKM menurut ketentuan Undang-Undang No. 20 Tahun 2008, lama UKM berdiri yaitu lebih dari 5 tahun, status histori penjualan tahunan UKM yang terus mengalami pengingkatan, dan jabatan dari responden ahli pada UKM terkait. Dari 5 panelis, 1 diantaranya menjabat 
Tabel 1.

Daftar layanan untuk pengembangan UKM

\begin{tabular}{|c|c|c|}
\hline No & Layanan & Kode \\
\hline \multicolumn{3}{|c|}{ Akses Pendanaan (A) } \\
\hline 1 & Akses kepada Investor & A1 \\
\hline 2 & Akses kepada Pendanaan Pemerintah & A2 \\
\hline 3 & Akses kepada Pinjaman Bank & A3 \\
\hline \multicolumn{3}{|c|}{ Bantuan Riset (R) } \\
\hline 4 & Riset Pasar & R1 \\
\hline 5 & Penilaian Produk oleh Pakar & R2 \\
\hline 6 & Penilaian Produk oleh Konsumen & R3 \\
\hline 7 & Proyeksi Bisnis & R4 \\
\hline 8 & Analisis Kehalalan Aktivitas Bisnis & R5 \\
\hline 9 & Analisis Aspek Manajemen Bisnis & R6 \\
\hline \multicolumn{3}{|c|}{ Dukungan Pengadaan Peralatan (D) } \\
\hline 10 & Dukungan Pengadaan Peralatan Sistem Informasi & D1 \\
\hline 11 & Dukungan Pengadaan Peralatan Produksi & D2 \\
\hline \multicolumn{3}{|c|}{ Dukungan Legalitas Usaha (L) } \\
\hline 12 & $\begin{array}{l}\text { Akses Jaringan dengan Pendampingan Pengurusan } \\
\text { Legalitas Usaha }\end{array}$ & L1 \\
\hline 13 & $\begin{array}{l}\text { Dukungan Pengurusan HKI/Hak Kekayaan } \\
\text { Intelektual }\end{array}$ & L3 \\
\hline \multicolumn{3}{|c|}{ Pelatihan dan Seminar (P) } \\
\hline 14 & Pelatihan Manajemen Keuangan Berkelanjutan & P1 \\
\hline 15 & Pelatihan terkait Pajak & $\mathrm{P} 2$ \\
\hline 16 & Pelatihan Pemasaran Produk & $\mathrm{P} 3$ \\
\hline 17 & Pelatihan Pembuatan Konten Pemasaran & P4 \\
\hline 18 & Pelatihan Manajemen SDM & P5 \\
\hline 19 & $\begin{array}{l}\text { Pelatihan Pengembangan Kepribadian } \\
\text { Kewirausahaan bagi Pemilik UKM }\end{array}$ & P6 \\
\hline 20 & Pelatihan untuk Peningkatan Kualitas Karyawan & P7 \\
\hline 21 & Pelatihan Manajemen Produksi dan Persediaan & P8 \\
\hline 22 & Pelatihan Pengurusan Legalitas Usaha & P9 \\
\hline 23 & Pelatihan yang diadakan secara Teratur & P10 \\
\hline 24 & Pelatihan yang bersifat Private & P11 \\
\hline 25 & Seminar Ilmu Bisnis Syariah & P12 \\
\hline No & Layanan & Kode \\
\hline \multicolumn{3}{|c|}{ Ruangan dan Fasilitas (RF) } \\
\hline 26 & Ruang Pameran Produk & RF1 \\
\hline 27 & Ruang Co-Working Space yang Gratis & RF2 \\
\hline 28 & Ruang Pelatihan & RF5 \\
\hline 29 & Ruang Perpustakaan & RF7 \\
\hline 30 & Ruang Perpustakaan dengan Jasa Konsultasi Gratis & RF8 \\
\hline 31 & Ruang Ibadah & RF9 \\
\hline 32 & Ruang Kantin & RF10 \\
\hline 33 & Ruangan dengan Fasilitas Internet & RF11 \\
\hline 34 & Lokasi Ruangan/Bangunan yang Strategis & RF12 \\
\hline \multicolumn{3}{|c|}{ Pendampingan oleh Pakar (PP) } \\
\hline 35 & Pendampingan Offline Berkelanjutan oleh Pakar & PP1 \\
\hline 36 & $\begin{array}{l}\text { Pendampingan Online Berkelanjutan oleh Pakar } \\
\text { Pendampingan Penggunaan Dana dari Pemberi }\end{array}$ & PP2 \\
\hline 37 & Dana & PP3 \\
\hline \multicolumn{3}{|c|}{ Akses Jaringan Usaha $(\mathrm{J})$} \\
\hline 38 & Akses Jaringan Pemasaran Offline & $\mathrm{J} 1$ \\
\hline & Akses Jaringan Pemasaran Offline dengan Jasa & $\mathrm{J} 2$ \\
\hline 39 & Pemasaran Online & \\
\hline 40 & Akses Jaringan Perusahaan Logistik & $\mathrm{J} 3$ \\
\hline 41 & Akses Business Matching Meeting & $\mathrm{J} 4$ \\
\hline & Akses Jaringan Pemasaran untuk Ekspansi Pasar & \\
\hline 42 & Internasional & $\mathrm{J} 5$ \\
\hline 43 & Akses Pameran Skala Nasional & $\mathrm{J} 6$ \\
\hline 44 & Akses Pameran Skala Internasional & $\mathrm{J} 7$ \\
\hline 45 & Akses Pameran yang Gratis & $\mathrm{J} 8$ \\
\hline 46 & Akses untuk Bekerjasama dengan Perguruan Tinggi & J9 \\
\hline 47 & Akses untuk Bekerjasama dengan Perusahaan Lain & $\mathrm{J} 10$ \\
\hline 48 & Akses Jaringan untuk Berkomunikasi dan & $\mathrm{J} 11$ \\
\hline 49 & $\begin{array}{l}\text { Berdiskusi dengan Perusahaan Lain } \\
\text { Akses kepada Perusahaan Rekruiter Karyawan } \\
\text { Berkualitas }\end{array}$ & $\mathrm{J} 12$ \\
\hline \multicolumn{3}{|c|}{$\begin{array}{l}\text { Layanan Pendukung (LP) } \\
\end{array}$} \\
\hline & Pembuatan Desain Grafis untuk Branding dan & \\
\hline 50 & Packaging & LP1 \\
\hline 51 & Perumusan Strategi Pemasaran & LP2 \\
\hline 52 & Pembuatan Konten Pemasaran & LP3 \\
\hline
\end{tabular}

Tabel 2 .

Hasil pembobotan kombinasi kategori dan layanan

\begin{tabular}{|c|c|c|c|c|}
\hline $\begin{array}{l}\text { Kategori } \\
\text { Layanan }\end{array}$ & $\begin{array}{c}\text { Sub } \\
\text { Layanan }\end{array}$ & $\begin{array}{c}\text { Bobot } \\
\text { Kategori } \\
\text { Layanan }\end{array}$ & $\begin{array}{c}\text { Bobot } \\
\text { Lokal Sub } \\
\text { Layanan }\end{array}$ & $\begin{array}{c}\text { Bobot } \\
\text { Global } \\
\text { Sub } \\
\text { Layanan }\end{array}$ \\
\hline \multirow{3}{*}{$\begin{array}{c}\text { Akses } \\
\text { Pendanaan }\end{array}$} & $\overline{\mathrm{A} 1}$ & \multirow[t]{3}{*}{0.103} & 0.417 & 0.043 \\
\hline & A2 & & 0.472 & 0.048 \\
\hline & A3 & & 0.112 & 0.012 \\
\hline \multirow{6}{*}{ Bantuan Riset } & R1 & \multirow[t]{6}{*}{0.101} & 0.171 & 0.017 \\
\hline & R2 & & 0.149 & 0.015 \\
\hline & R3 & & 0.168 & 0.017 \\
\hline & R4 & & 0.189 & 0.019 \\
\hline & R5 & & 0.154 & 0.016 \\
\hline & R6 & & 0.168 & 0.017 \\
\hline Dukungan & D1 & \multirow[t]{2}{*}{0.083} & 0.514 & 0.043 \\
\hline $\begin{array}{c}\text { Pengadaan } \\
\text { Peralatan }\end{array}$ & D2 & & 0.486 & 0.040 \\
\hline \multirow{2}{*}{$\begin{array}{l}\text { Dukungan } \\
\text { Legalitas } \\
\text { Usaha }\end{array}$} & L1 & \multirow[t]{2}{*}{0.080} & 0.450 & 0.036 \\
\hline & L3 & & 0.550 & 0.044 \\
\hline \multirow{12}{*}{$\begin{array}{l}\text { Pelatihan dan } \\
\text { Seminar }\end{array}$} & P1 & \multirow[t]{5}{*}{0.097} & 0.090 & 0.009 \\
\hline & P2 & & 0.046 & 0.004 \\
\hline & P3 & & 0.156 & 0.015 \\
\hline & P4 & & 0.122 & 0.012 \\
\hline & P5 & & 0.067 & 0.007 \\
\hline & P6 & \multirow[t]{7}{*}{0.097} & 0.072 & 0.007 \\
\hline & P7 & & 0079 & 0.008 \\
\hline & P8 & & 0.112 & 0.11 \\
\hline & P9 & & 0.053 & 0.005 \\
\hline & P10 & & 0.080 & 0.008 \\
\hline & P11 & & 0.063 & 0.006 \\
\hline & P12 & & 0.060 & 0.006 \\
\hline \multirow{9}{*}{$\begin{array}{l}\text { Ruangan dan } \\
\text { Fasilitas }\end{array}$} & RF1 & \multirow[t]{9}{*}{0.051} & 0.163 & 0.008 \\
\hline & RF2 & & 0.150 & 0.008 \\
\hline & RF5 & & 0.114 & 0.006 \\
\hline & RF7 & & 0.039 & 0.002 \\
\hline & RF8 & & 0.092 & 0.005 \\
\hline & RF9 & & 0.140 & 0.007 \\
\hline & RF10 & & 0.055 & 0.003 \\
\hline & RF11 & & 0.081 & 0.004 \\
\hline & RF12 & & 0.162 & 0.008 \\
\hline \multirow{3}{*}{$\begin{array}{l}\text { Pendampingan } \\
\text { oleh Pakar }\end{array}$} & PP1 & \multirow[t]{3}{*}{0.214} & 0.466 & 0.100 \\
\hline & PP2 & & 0.245 & 0.052 \\
\hline & PP3 & & 0.289 & 0.062 \\
\hline \multirow{12}{*}{$\begin{array}{c}\text { Akses Jaringan } \\
\text { Usaha }\end{array}$} & J1 & \multirow[t]{12}{*}{0.160} & 0.046 & 0.007 \\
\hline & $\mathrm{J} 2$ & & 0.066 & 0.011 \\
\hline & $\mathrm{J} 3$ & & 0.032 & 0.005 \\
\hline & $\mathrm{J} 4$ & & 0.094 & 0.015 \\
\hline & J5 & & 0.131 & 0.021 \\
\hline & J6 & & 0.121 & 0.019 \\
\hline & J7 & & 0.128 & 0.020 \\
\hline & $\mathrm{J} 8$ & & 0.090 & 0.014 \\
\hline & J9 & & 0.088 & 0.014 \\
\hline & $\mathrm{J} 10$ & & 0.077 & 0.012 \\
\hline & J11 & & 0.076 & 0.012 \\
\hline & $\mathrm{J} 12$ & & 0.052 & 0.008 \\
\hline \multirow{3}{*}{$\begin{array}{l}\text { Layanan } \\
\text { Pendukung }\end{array}$} & LP1 & \multirow[t]{3}{*}{0.112} & 0.331 & 0.037 \\
\hline & LP2 & & 0.350 & 0.039 \\
\hline & LP3 & & 0.319 & 0.036 \\
\hline
\end{tabular}

sebagai general manager pada UKM. Sedangkan 4 panelis merupakan pemilik dari UKM.

\section{B. Analisis Konten}

Pengolahan data hasil wawancara pada generative round metode Delphi dilakukan dengan menganalisis konten dari transkip wawancara yang telah diperoleh. Analisis konten diawali dengan membaca secara berulang-ulang transkip wawancara untuk memahami secara baik respon dari setiap panelis terhadap pertanyaan yang diajukan oleh peneliti sebagai pewawancara. Setelah memahami transkip dengan baik, tahap selanjutnya adalah mengidentifikasi kode layanan 
Prioritas Layanan Pengembangan UKM pada Lembaga Pengembangan Bisnis

\begin{tabular}{|c|c|c|c|c|c|c|c|c|}
\hline $\mathrm{A}$ & $R$ & D & $\mathrm{L}$ & P & RF & PP & $\mathrm{J}$ & LP \\
\hline \begin{tabular}{|l|}
$\mathrm{A} 1$ \\
\end{tabular} & \begin{tabular}{|l} 
R1 \\
\end{tabular} & \begin{tabular}{|l|} 
D1 \\
\end{tabular} & \begin{tabular}{|l|}
$\mathrm{L1}$ \\
\end{tabular} & $P 1$ & \begin{tabular}{|l|l} 
RF1 \\
\end{tabular} & \begin{tabular}{|l|l} 
PP1 \\
\end{tabular} & \begin{tabular}{|l}
$\mathrm{J} 1$ \\
\end{tabular} & \begin{tabular}{|l} 
LP1 \\
\end{tabular} \\
\hline $\begin{array}{ll}\mathrm{A} 2 \\
\end{array}$ & \begin{tabular}{|l}
$\mathrm{R} 2$ \\
\end{tabular} & D2 & 4 & $\mathrm{P}_{2}$ & \begin{tabular}{|l|l|} 
RF2 \\
\end{tabular} & \begin{tabular}{|l} 
PP2 \\
\end{tabular} & \begin{tabular}{|l|l}
$\mathrm{J} 2$ \\
\end{tabular} & \begin{tabular}{|l|l|} 
LP2 & \\
\end{tabular} \\
\hline A33 & \begin{tabular}{|l} 
R3 \\
\end{tabular} & & & P3 & \begin{tabular}{|l|} 
RF5 \\
\end{tabular} & PP3 & $\mathrm{J3}$ & LP3 \\
\hline & R4 & & & P4 & \begin{tabular}{|l} 
RF7 \\
\end{tabular} & & $\mathrm{J4}$ & \\
\hline & \begin{tabular}{|l} 
R55 \\
\end{tabular} & & & P5 & \begin{tabular}{|l} 
RF8 \\
\end{tabular} & & \begin{tabular}{|l|l}
$\mathrm{J} 5$ \\
\end{tabular} & \\
\hline & R6 & & & P6 & \begin{tabular}{|l|} 
RF9 \\
\end{tabular} & & $\mathrm{J} 6$ & \\
\hline & & & & P7 & RF10 & & $\mathrm{J7}$ & \\
\hline & & & & P8 & \begin{tabular}{|l} 
RF11 \\
\end{tabular} & & \begin{tabular}{|l}
$\mathrm{J} 8$ \\
\end{tabular} & \\
\hline & & & & P9 & LFF12 & & \begin{tabular}{|l} 
J99 \\
\end{tabular} & \\
\hline & & & & \begin{tabular}{|l} 
P10 \\
\end{tabular} & & & \begin{tabular}{|l} 
J10 \\
\end{tabular} & \\
\hline & & & & \begin{tabular}{|l} 
P11 \\
\end{tabular} & & & \begin{tabular}{|l} 
J11 \\
\end{tabular} & \\
\hline & & & & P12 & & & J12 & \\
\hline
\end{tabular}

Gambar 1. Model hirarki AHP

dan kategori dari setiap layanan. Sehingga diperoleh 9 kategori layanan dengan 56 kode layanan untuk pengembangan UKM pada lembaga pengembangan bisnis.

\section{Hasil Pengolahan Data Kuesioner Delphi}

Setelah diperoleh daftar layanan pengembangan UKM, selanjutnya dilakukan putaran survei melalui penyebaran kuesioner skala likert 5 poin. Kuesioner berisi pernyataan terkait kode layanan yang diperlukan untuk pengembangan UKM, dimana panelis diminta untuk memberikan penilaian tingkat persetujuan terhadap setiap pernyataan. Setelah data penilaian terkumpul, pengolahan data hasil kuesioner dilakukan menggunakan aplikasi Microsoft Excel dengan perhitungan nilai median dan IQR.

Hasil pengolahan data putaran Delphi kedua menunjukkan bahwa terdapat 9 kode layanan yang tidak mencapai konsensus, sehingga perlu untuk dinilai kembali pada putaran Delphi ketiga. Pada putaran Delphi ketiga, penilaian dilakukan melalui kuesioner yang terdiri atas pernyataan dari 9 kode layanan, hasil pengolahan data pada putaran Delphi kedua, dan catatan penilaian setiap pernyataan pada kuesioner Delphi kedua. Panelis diminta kembali untuk menilai tingkat persetujuan skala likert 5 poin terhadap setiap pernyataan terkait kode layanan yang belum mencapai konsensus pada putaran survei kedua dengan memperhatikan catatan penilaian putaran Delphi sebelumnya. Hasil pengumpulan data Delphi putaran ketiga kemudian diolah kembali menggunakan Microsoft Excel dengan perhitungan nilai median dan IQR.

Hasil pengolahan data Delphi putaran ketiga menunjukkan bahwa dari 9 kode layanan ya ng dinilai kembali oleh panelis terdapat 5 kode layanan yang telah mencapai konsensus, sedangkan 4 lainnya tidak $m$ encapai konsensus dan kemudian dieliminasi dari daftar layanan untuk pengembangan UKM. Sehingga putaran Delphi berakhir pada Delph i putaran ketiga dengan total 9 kategori layanan dan 52 kode layanan pengembangan UKM seperti pada Tabel 1 .

\section{Konstruksi Model Hirarki AHP}

Setelah memperoleh daftar layanan pengembangan UKM, kemudian dilakukan penentuan prioritas layanan menggunakan kuesioner perbandingan berpasangan AHP. Kuesioner AHP menggunakan skala perbandingan berpasangan 9 poin. Langkah pertama yang dilakukan dalam
Tabel 3.

Tingkat rasio konsistensi kombinasi

\begin{tabular}{lcc}
\hline \hline \multicolumn{1}{c}{ Kategori Layanan } & $\begin{array}{c}\text { Rasio Konsistensi Per } \\
\text { Kategori Layanan }\end{array}$ & $\begin{array}{c}\text { Rasio Konsistensi } \\
\text { Keseluruhan }\end{array}$ \\
\hline Akses Pendanaan & 0.03 & \\
Bantuan Riset & 0.03 & \\
$\begin{array}{l}\text { Dukungan Pengadaan } \\
\text { Peralatan }\end{array}$ & 0.00 & 0.03 \\
$\begin{array}{l}\text { Dukungan Legalitas } \\
\text { Usaha }\end{array}$ & 0.00 & \\
Pelatihan dan Seminar & 0.03 & \\
Ruangan dan Fasilitas & 0.04 & \\
Pendampingan oleh & 0.00045 & \\
Pakar & 0.04 & \\
Akses Jaringan Usaha & 0.00 & \\
Layanan Pendukung & & \\
\hline \hline
\end{tabular}

Tabel 4.

Peringkat prioritas kategori layanan

\begin{tabular}{clc}
\hline \hline Peringkat Prioritas & \multicolumn{1}{c}{ Kategori Layanan } & Bobot \\
\hline 1 & Pendampingan oleh Pakar & 0.214 \\
2 & Akses Jaringan Usaha & 0.160 \\
3 & Layanan Pendukung & 0.112 \\
4 & Akses Pendanaan & 0.103 \\
5 & Bantuan Riset & 0.101 \\
6 & Pelatihan dan Seminar & 0.097 \\
7 & Dukungan Pengadaan Peralatan & 0.083 \\
8 & Dukungan Legalitas Usaha & 0.080 \\
9 & Ruangan dan Fasilitas & 0.051 \\
\hline \hline
\end{tabular}

Tabel 5.

Bobot prioritas layanan pada kategori pendampingan oleh pakar

\begin{tabular}{clc}
\hline \hline No. & \multicolumn{1}{c}{ Layanan } & $\begin{array}{c}\text { Bobot } \\
\text { Lokal }\end{array}$ \\
\hline 1 & $\begin{array}{l}\text { Pendampingan Offline Berkelanjutan oleh } \\
\text { Pakar }\end{array}$ & 0.466 \\
2 & $\begin{array}{l}\text { Pendampingan Online Berkelanjutan oleh } \\
\text { Pakar }\end{array}$ & 0.245 \\
3 & $\begin{array}{l}\text { Pendampingan Penggunaan Dana dari } \\
\text { Pemberi Dana }\end{array}$ & 0.289 \\
\hline \hline
\end{tabular}

metode AHP adalah penyusunan model hirarki AHP yang ditunjukkan pada Gambar 1. Output dari hirarki ini adalah daftar prioritas layanan pengembangan UKM pada lembaga pengembangan bisnis, baik inkubator bisnis maupun BDS-P.

\section{E. Penentuan Responden Kuesioner AHP}

Pemilihan responden ahli dari UKM memperhatikan definisi UKM yang sesuai dengan ketentuan Undang-Undang No. 20 Tahun 2008, berumur lebih dari 5 tahun, dan memiliki histori omset yang terus meningkat dari tahun ke tahun. Sedangkan pemilihan responden ahli dari akademisi dan praktisi didasarkan atas bidang ahli dan lama bekerja pada bidang terkait. Penentuan responden ahli pada bagian ini adalah untuk penilaian kuesioner perbandingan relatif berpasangan AHP yang terdiri atas 5 responden ahli dari UKM, 1 responden ahli yaitu seorang akademisi bidang kewirausahaan, dan 2 responden ahli yaitu seorang praktisi pada lembaga pengembangan bisnis.

\section{F. Hasil Pembobotan Layanan Pengembangan UKM}

Berdasarkan hasil penilaian perbandingan berpasangan oleh responden ahli, maka dapat diperoleh bobot tingkat kepentingan dari masing-masing kriteria dan sub-kriteria layanan pengembangan UKM pada lembaga pengembangan bisnis. Pembobotan dilakukan menggunakan aplikasi Expert Choice dengan memasukkan data penilaian dari seluruh responden ahli kedalam aplikasi Expert Choice untuk melihat tingkat kepentingan layanan pengembangan UKM pada 
Tabel 6.

Bobot prioritas layanan pada kategori akses jaringan usaha

\begin{tabular}{|c|c|c|}
\hline No. & Layanan & $\begin{array}{l}\text { Bobot } \\
\text { Lokal }\end{array}$ \\
\hline 1 & Akses Jaringan Pemasaran Offline & 0.046 \\
\hline 2 & $\begin{array}{l}\text { Akses Jaringan Pemasaran Offline dengan Jasa } \\
\text { Pemasaran Online }\end{array}$ & 0.066 \\
\hline 3 & Akses Jaringan Perusahaan Logistik & 0.032 \\
\hline 4 & Akses Business Matching Meeting & 0.094 \\
\hline 5 & $\begin{array}{l}\text { Akses Jaringan Pemasaran untuk Ekspansi } \\
\text { Pasar Internasional }\end{array}$ & 0.131 \\
\hline 6 & Akses Pameran Skala Nasional & 0.121 \\
\hline 7 & Akses Pameran Skala Internasional & 0.128 \\
\hline 8 & Akses Pameran yang Gratis & 0.090 \\
\hline 9 & $\begin{array}{l}\text { Akses untuk Bekerjasama dengan Perguruan } \\
\text { Tinggi }\end{array}$ & 0.088 \\
\hline 10 & $\begin{array}{l}\text { Akses untuk Bekerjasama dengan Perusahaan } \\
\text { Lain }\end{array}$ & 0.077 \\
\hline 11 & $\begin{array}{l}\text { Akses untuk Berkomunikasi dan Berdiskusi } \\
\text { dengan Perusahaan Lain }\end{array}$ & 0.076 \\
\hline 12 & $\begin{array}{l}\text { Akses kepada Perusahaan Recruiter Karyawan } \\
\text { Berkualitas }\end{array}$ & 0.052 \\
\hline
\end{tabular}

berbagai lembaga pengembangan bisnis, baik inkubator bisnis maupun BDS-P. Tabel 2 menyajikan hasil pembobotan kombinasi kategori layanan dan sub layanan pengembangan UKM yang dilakukan menggunakan aplikasi Expert Choice dengan tingkat konsistensi yang ditunjukkan pada Tabel 3.

Dari hasil uji konsistensi dapat dilihat bahwa keseluruhan rasio konsistensi, baik rasio konsistensi total dan per kategori layanan adalah kurang dari 0,1 . Hal ini menunjukkan bahwa hasil pembobotan yang dilakukan terhadap kategori layanan dan layanan untuk pengembangan UKM pada lembaga pengembangan bisnis dapat diandalkan.

\section{G. Analisis Prioritas Kategori Layanan}

Berdasarkan hasil pembobotan kombinasi pada Tabel 2, dapat diketahui bobot dari masing-masing kategori layanan berdasarkan urutan prioritas layanan untuk pengembangan UKM pada lembaga pengembangan bisnis, seperti pada Tabel 4. Sehingga dapat diketahui 5 prioritas layanan pengembangan UKM pada lembaga pengembangan bisnis, baik inkubator bisnis maupun BDS-P yang meliputi layanan pendampingan oleh pakar, akses jaringan usaha, layanan pendukung, akses pendanaan, dan bantuan riset.

\section{1) Analisis Hasil Pembobotan Kombinasi Kategori} Pendampingan oleh Pakar

Kategori pendampingan oleh pakar merupakan layanan yang paling mendominasi diantara layanan-layanan lain. Hal ini menunjukkan bahwa kategori layanan berupa pendampingan oleh pakar merupakan layanan dari lembaga pengembangan bisnis yang penting untuk membantu UKM berkembang di dunia kewirausahaan yang tidak tentu dan pasar yang semakin kompetitif saat ini. Pernyataan tersebut didukung oleh penelitian terdahulu yang menyatakan bahwa pendampingan oleh pakar berpengaruh positif terhadap performansi, pengembangan operasional, dan inovasi suatu bisnis $[25,26]$ serta merupakan program pendampingan yang penting dalam proses manajemen pengetahuan pada UKM [27] dengan memberikan nilai tambah dalam mendukung pengalaman pembelajaran bagi UKM [28].

Peran mentor dan coach sebagai pendamping yang memiliki kompetensi, pengetahuan, dan pengalaman dalam dunia kewirausahana diperlukan untuk membantu dan memotivasi UKM [29] serta sebagai media transfer knowledge [30]. Di lain sisi, alasan pendampingan oleh pakar merupakan layanan yang penting untuk pengembangan UKM dikarenakan $80 \%$ tingkat kegagalan UKM di Indonesia
Tabel 7.

Bobot prioritas layanan pada kategori layanan pendukung

\begin{tabular}{clc}
\multicolumn{1}{c}{ Layanan } & $\begin{array}{c}\text { Bobot } \\
\text { Lokal }\end{array}$ \\
\hline \hline No. & \multicolumn{1}{c}{0.331} \\
\hline 1 & $\begin{array}{l}\text { Pembuatan Desain untuk Branding dan } \\
\text { Packaging }\end{array}$ & 0.350 \\
2 & Perumusan Strategi Pemasaran & 0.319 \\
3 & Pembuatan Konten Pemasaran & \\
\hline \hline
\end{tabular}

Tabel 8.

Bobot prioritas layanan pada kategori akses pendanaan

\begin{tabular}{clc}
\hline \hline No. & \multicolumn{1}{c}{ Layanan } & $\begin{array}{c}\text { Bobot } \\
\text { Lokal }\end{array}$ \\
\hline 1 & Akses kepada Investor & 0.417 \\
2 & Akses kepada Pendanaan Pemerintah & 0.472 \\
3 & Akses kepada Pinjaman Bank & 0.112 \\
\hline \hline
\end{tabular}

Tabel 9.

Bobot prioritas layanan pada kategori bantuan riset

\begin{tabular}{clc}
\hline & Bobot prioritas layanan pada kategori bantuan riset \\
\hline \hline No. & \multicolumn{1}{c}{ Layanan } & $\begin{array}{c}\text { Bobot } \\
\text { Lokal }\end{array}$ \\
\hline 1 & Riset Pasar & 0.171 \\
2 & Penilaian Produk oleh Pakar & 0.149 \\
3 & Penilaian Produk oleh Konsumen & 0.168 \\
4 & Proyeksi Bisnis & 0.189 \\
5 & Analisis Kehalalan Aktivitas Bisnis & 0.154 \\
\hline 6 & Analisis Aspek Manajemen Bisnis & 0.168 \\
\hline \hline
\end{tabular}

disebabkan oleh kurangnya pendampingan oleh pakar [8]. Hal ini juga telah didukung oleh penelitian terdahulu yang menyatakan bahwa program pendampingan oleh pakar menjadi salah satu cara untuk mengatasi kegagalan UKM [31].

Pada penelitian ini, kategori pendampingan oleh pakar terdiri atas 3 layanan yaitu pendampingan offline berkelanjutan oleh pakar, pendampingan online berkelanjutan oleh pakar, serta pendampingan penggunaan dana dari pemberi dana. Berdasarkan hasil pembobotan kombinasi layanan pada kategori pendampingan oleh pakar, dapat diketahui layanan pendampingan offline berkelanjutan oleh pakar merupakan layanan pada kategori pendanaan yang paling diperlukan untuk pengembangan UKM pada lembaga pengembangan bisnis. Kemudian diikuti oleh pendampingan penggunaan dana dari pemberi dana dan pendampingan online berkelanjutan oleh pakar seperti pada Tabel 5 . Sehingga pada kategori layanan pendampingan oleh pakar, pendampingan secara online kurang diperlukan oleh UKM dalam proses pengembangan usahanya.

\section{2) Analisis Hasil Pembobotan Kombinasi Kategori Akses} Jaringan Usaha

Akses jaringan usaha merupakan layanan yang juga penting dalam pengembangan UKM. Hal ini didukung oleh penelitian terdahulu yang menyatakan bahwa jaringan usaha dapat memberikan dampak positif pada performansi dan kinerja UKM yang sukses [32, 33]. Jaringan usaha, baik yang bersifat lokal maupun internasional dapat memungkinkan UKM untuk belajar dari pengalaman, memperoleh peluang dan pengetahuan baru, serta mendapat manfaat dari efek sinergis pada jaringan bisnis yang luas [34].

Jaringan usaha yang dimiliki UKM tidak hanya sebatas pada jaringan antar UKM sehingga menjadi tempat pertukaran informsi, tapi jaringan bisnis bagi UKM juga akan menuntun perusahaan untuk mendapatkan lebih banyak klien, pemegang saham, rekan bisnis, pemasok, tenaga kerja, pengetahuan teknis dan pasar, kepercayaan, bimbingan bisnis, penyelesaian masalah $[35,36]$, penciptaan inovasi, reputasi yang baik [35], dan akses atas teknologi [37]. 
Sehingga UKM dapat bertahan dan meningkatkan keunggulan kompetitif produk dan jasa yang ditawarkan.

Pada penelitian ini, kategori akses jaringan usaha terdiri atas 12 layanan. Berdasarkan hasil pembobotan kombinasi layanan pada kategori akses jaringan usaha, dapat diketahui 5 layanan yang paling diperlukan untuk pengembangan UKM pada kategori akses jaringan usaha yaitu akses jaringan pemasaran untuk ekspansi pasar internasional sebagai layanan pengembangan UKM yang paling diperlukan. Kemudian diikuti oleh akses pameran skala internasional, akses pameran skala nasional, akses business matching meeting, dan akses pameran yang gratis seperti pada Tabel 6 . 3) Analisis Hasil Pembobotan Kombinasi Kategori Layanan Pendukung

Layanan pendukung pada penelitian ini merupakan layanan berupa bantuan teknis untuk mendukung proses bisnis dari UKM yang terdiri atas pembuatan desain untuk branding maupun packaging, perumusan strategi pemasaran, dan pembuatan konten pemasaran. Layanan pendukung ini menjadi salah satu prioritas layanan yang diperlukan oleh UKM dalam proses pengembangan usahanya, dimana layanan pendukung ini disediakan oleh lembaga pengembangan bisnis. Hal ini disebabkan oleh kurangnya kemampuan pelaku usaha UKM terkait desain khususnya untuk pembuatan desain untuk branding dan packaging, strategi pemasaran, dan pembuatan konten pemasaran yang menarik yang disebabkan oleh pendidikan pelaku usaha UKM yang rendah dan kurangnya keterampilan dari pelaku usaha UKM [38-40]. Terdapat opsi lain yang dapat ditempuh untuk memperoleh layanan pendukung ini yaitu melalui penggunaan jasa dari tenaga atau lembaga ahli. Namun walaupun terdapat orang ahli atau lembaga yang menyediakan jasa pembuatan brand dan packaging, perumusan strategi pemasaran, dan pembuatan konten pemasaran, terdapat kendala lain yang menghambat UKM yaitu masalah terbatasnya modal yang dimiliki [41].

Berdasarkan hasil pembobotan kombinasi layanan pada kategori layanan pendukung, dapat diketahui perumusan strategi pemasaran merupakan layanan pada kategori layanan pendukung yang paling diperlukan untuk pengembangan UKM pada lembaga pengembangan bisnis. Kemudian diikuti oleh layanan pembuatan desain untuk branding dan packaging dan layanan pembuatan konten pemasaran seperti pada Tabel 7 .

4) Analisis Hasil Pembobotan Kombinasi Kategori Akses Pendanaan

Akses pendanaan menjadi salah satu kategori layanan yang penting dan diperlukan UKM untuk pengembangan UKM dikarenakan pada umumnya UKM tidak memiliki cukup dana dan informasi terkait sumber pendanaan [42] sehingga pendanaan juga merupakan salah satu penyebab dari kegagalan UKM [41]. Selain itu akses pendanan menjadi salah satu syarat suatu UKM dapat tercipta, beroperasi, dan berkembang. Hal ini dapat diwajari dan dapat dilihat pada bukti-bukti penelitian terdahulu yaitu penelitian Hartsenko dan Sauga [43] yang mengatakan bahwa pendanaan merupakan elemen penting dalam UKM untuk penciptaan, keberlangsungan, dan perkembangan dari suatu usaha dengan meningkatkan daya saing perusahaan. Penelitian Eriksson [44] juga menyatakan bahwa kebutuhan akan pendanaan akan terus ada seiring berjalannya waktu pada UKM, karena dalam proses $\mathrm{p}$ engembangan UKM, UKM perlu untuk melakukan investasi dibebarapa bidang yang berbeda seperti
Tabel 10 .

Prioritas sub layanan pengembangan UKM

\begin{tabular}{clc}
\hline \hline $\begin{array}{c}\text { Peringkat } \\
\text { Prioritas }\end{array}$ & \multicolumn{1}{c}{ Layanan } & $\begin{array}{c}\text { Bobot } \\
\text { Global }\end{array}$ \\
\hline 1 & $\begin{array}{l}\text { Pendampingan Offline } \text { Berkelanjutan oleh } \\
\text { Pakar }\end{array}$ & 0.100 \\
2 & $\begin{array}{l}\text { Pendampingan Penggunaan Dana dari } \\
\text { Pemberi Dana }\end{array}$ & 0.062 \\
& $\begin{array}{l}\text { Pendampingan Online Berkelanjutan oleh } \\
3\end{array}$ & 0.052 \\
4 & Pakar & 0.048 \\
5 & Akses kepada Pendanaan Pemerintah & 0.044 \\
& $\begin{array}{l}\text { Dukungan Pengurusan HKI/Hak Kekayaan } \\
\text { Intelektual }\end{array}$ & 0.043 \\
7 & $\begin{array}{l}\text { Akses kepada Investor } \\
\text { Dukungan Pengadaan Peralatan Sistem }\end{array}$ & 0.043 \\
8 & $\begin{array}{l}\text { Informasi } \\
\text { Dukungan Pengadaan Peralatan Produksi }\end{array}$ & 0.040 \\
9 & Perumusan Strategi Pemasaran & 0.039 \\
10 & Pembuatan Desain untuk branding dan & 0.037 \\
\hline \hline
\end{tabular}

peningkatan kapasitas, pengembangan pasar, dan pengembangan teknologi.

Pada penelitian ini, kategori akses pendanaan terdiri atas 3 layanan yaitu akses kepada investor, akses kepada pendanaan pemerintah, dan akses kepada pinjaman bank. Berdasarkan hasil pembobotan kombinasi layanan pada kategori akses pendanaan, dapat diketahui layanan akses kepada pendanaan pemerintah merupakan layanan pada kategori akses pendanaan yang paling diperlukan oleh UKM untuk pengembangan UKM pada lembaga pengembangan bisnis. Kemudian diikuti oleh akses kepada investor dan akses kepada pinjaman bank seperti pada Tabel 8 .

5) Analisis Hasil Pembobotan Kombinasi Kategori Bantuan Riset

Dalam proses pengembangan UKM, UKM menghadapi lingkungan kewirausahaan kompetitif yang sangat dinamik, satu-satunya hal yang konstan adalah adanya perubahan yang terus terjadi secara tak tentu. Perubahan tersebut seperti perubahan preferensi konsumen, peningkatan teknologi inovasi, persaingan yang ketat dan pasar yang semakin luas menuntut pemasar untuk terus mengikuti perkembangannya dengan mengadopsi strategi yang tepat agar sebuah usaha dapat tetap bertahan di pasar. Untuk dapat menentukan strategi yang tepat, diperlukan data-data yang dapat menunjang proses pengambilan keputusan pada UKM, dimana riset merupakan metode yang digunakan untuk proses pengumpulan, analisis, dan penerjemahan informasi akan suatu kejadian atau fenomena secara sistematis untuk menambah pengetahuan [45]. Oleh karena itu, riset merupakan hal yang penting bagi UKM. Namun pada kenyataan, penggunaan data pada pengambilan keputusan UKM masih sangat rendah. Hal tersebut disebabkan oleh kurangnya pengetahuan dan kompetensi dari pelaku usaha UKM [38-40]. Sehingga, layanan berupa bantuan riset merupakan layanan yang penting dan diperlukan oleh UKM.

Pada penelitian ini, kategori bantuan riset terdiri atas 6 layanan yaitu riset pasar, penilaian produk oleh pakar atau kurasi produk, penilaian produk oleh konsumen, proyeksi bisnis, analisis kehalalan aktivitas bisnis, dan analisis fungsi manajemen bisnis. Berdasarkan hasil pembobotan kombinasi layanan pada kategori bantuan riset yang dilakukan menggunakan aplikasi Expert Choice, dapat diketahui 3 layanan pada kategori bantuan riset yang paling diprioritaskan oleh UKM untuk pengembangan UKM yaitu diantaranya proyeksi bisnis, riset pasar, dan analisis fungsi manajemen bisnis seperti pada Tabel 9. 


\section{H. Analisis Prioritas Sub Layanan}

Pada penelitian ini, terdapat 9 kategori layanan dengan 52 sub-kategori yang diperlukan untuk pengembangan UKM pada lembaga pengembangan bisnis. Peringkat prioritas sub layanan terhadap tujuan hirarki penelitian didasarkan atas bobot global masing-masing sub layanan yang dapat dilihat pada Tabel 2. Berdasarkan Tabel 2, dapat diidentifikasi 10 sub layanan yang paling diperlukan untuk pengembangan UKM pada lembaga pengembangan bisnis, selanjutnya ditampilkan pada Tabel 10 dengan tingkat konsistensi 0.03. Nilai rasio konsistensi tersebut menunjukkan bahwa hasil penilaian responden pada kategori pendampingan oleh pakar sudah konsisten dan dapat diandalkan.

Berdasarkan Tabel 10 diketahui bahwa 3 layanan pertama yaitu pendampingan offline berkelanjutan oleh pakar pada peringkat prioritas pertama, pendampingan penggunaan dana dari pemberi dana pada peringkat prioritas kedua, dan pendampingan online berkelanjutan oleh pakar pada peringkat prioritas ketiga merupakan layanan pada kategori pendampingan oleh pakar. Sehingga pendampingan oleh pakar merupakan kategori layanan yang paling diperlukan oleh UKM untuk pengembangan UKM pada lembaga pengembangan bisnis, baik inkubator bisnis maupun BDS-P. Kemudian pada peringkat 4 dan 6 yaitu layanan akses kepada pendanaan pemerintah dan akses kepada investor merupakan sub layanan pada ketegori akses pendanaan, sehingga kategori layanan akses pendanaan merupakan layanan yang diperlukan oleh UKM untuk pengembangan UKM. Pada peringkat 5 yaitu dukungan pengurusan HKI/Hak Kekayaan Intelektual merupakan sub layanan pada kategori dukungan legalitas usaha. Pada peringkat 7 dan 8 yaitu dukungan pengadaan peralatan sistem informasi dan dukungan pengadaan peralatan produksi yang merupakan sub layanan dari kategori dukungan pengadaan peralatan. Selanjutnya pada peringkat 9 dan 10 yaitu perumusan strategi pemasaran serta pembuatan desain untuk branding dan packaging merupakan sub layanan pada kategori layanan pendukung.

\section{KESIMPULAN}

Berdasarkan hasil analisis, diketahui bahwa terdapat 9 kategori dengan 52 layanan yang diperlukan untuk pengembangan UKM pada lembaga pengembangan bisnis, baik inkubator bisnis maupun BDS-P. 9 kategori layanan tersebut meliputi akses pendanaan, bantuan riset, dukungan pengadaan peralatan, dukungan legalitas usaha, pelatihan dan seminar, pendampingan oleh pakar, ruangan dan fasilitas, akses jaringan usaha, dan layanan pendukung.

Kemudian hasil pembobotan menunjukkan bahwa 5 layanan yang paling diprioritaskan untuk pengembangan UKM meliputi pendampingan oleh pakar, akses jaringan usaha, layanan pendukung, akses pendanaan, dan bantuan riset. Layanan pada kategori pendampingan oleh pakar yang paling diprioritaskan adalah pendapingan offline oleh pakar dan pendampingan penggunaan dana oleh pakar. Layanan pada kategori akses jaringan usaha yang paling diprioritaskan adalah akses jaringan pemasaran untuk ekspansi pasar internasional, akses pameran internasional, akses pameran nasional, dan akses business matching meeting. Layanan pada kategori layanan pendukung yang paling diprioritaskan adalah perumusan strategi pemasaran dan pembuatan desain untuk branding dan packaging. Layanan pada akses pendanaan adalah akses kepada pendanaan pemerintah dan akses kepada investor. Sedangkan layanan pada kategori bantuan riset yang diperlukan adalah proyeksi bisnis, riset pasar, dan analisis fungsi manajemen bisnis.

\section{DAFTAR PUSTAKA}

[1] Biro Kredit Bank Indonesia, "Kajian Inkubator Bisnis dalam rangka Pengembangan UMKM," Jakarta (ID): Tim Penelitian dan Pengembangan Biro Kredit BI, 2006.

[2] Kementerian Koperasi dan UKM, "Perkembangan Data Usaha Mikro, Kecil, Menengah (UMKM) dan Usaha Besar (UB) Tahun 2012-2013," 2013.

[3] J. A. Belso-Martinez, F. X. Molina-Morales, and F. Mas-Verdu, "Combining effects of internal resources, entrepreneur characteristics and KIS on new firms," Journal of Business Research, vol. 66, no. 10 , pp. 2079-2089, 2013.

[4] Y. Honjo, "Business failure of new firms: an empirical analysis using a multiplicative hazards model," International Journal of Industrial Organization, vol. 18, no. 4, pp. 557-574, 2000.

[5] Sutrisno, Manajemen Sumber Daya Manusia. Jakarta: Pranada Media Group, 2014.

[6] H. Syarief, B. M. R. P, Ed., ed, 2019.

[7] S. Urata, Policy recommendation for SME promotion in the Republic of Indonesia. JICA, 2000.

[8] E. Suryowati, "Pelaku Usaha UMKM Gagal karena Minim Pendampingan," in Kompas.com, ed, 2014.

[9] "Peraturan Presiden Republik Indonesia Nomor 27 Tahun 2013," ed. Indonesia, 2013.

[10] "Peraturan Menteri Negara Koperasi dan UKM Republik Indonesia Nomor 02 Tahun 2008," ed, 2008.

[11] M. Lukeš, M. C. Longo, and J. Zouhar, "Do business incubators really enhance entrepreneurial growth? Evidence from a large sample of innovative Italian start-ups," Technovation, 2018.

[12] A. K. Meru and M. Struwig, "An evaluation of the entrepreneurs' perception of business-incubation services in Kenya," International Journal of Business Administration, vol. 2, no. 4, p. 112, 2011.

[13] W.-H. Lai and C.-C. Lin, "Constructing business incubation service capabilities for tenants at post-entrepreneurial phase," Journal of Business Research, vol. 68, no. 11, pp. 2285-2289, 2015.

[14] J. Bruneel, T. Ratinho, B. Clarysse, and A. Groen, "The Evolution of Business Incubators: Comparing demand and supply of business incubation services across different incubator generations," Technovation, vol. 32, no. 2, pp. 110-121, 2012.

[15] I. D. Nurhayati, "Analisis Keserasian Program Layanan Business Development Service-Provider (BDS-P) dengan Peraturan Pemerintah terkait Pengembangan Usaha Mikro Kecil dan Menengah (UMKM) di Jawa Timur," Jurnal Manajemen dan Akuntansi, vol. 3, no. 3, 2014.

[16] N. Imamah, "Peranan Business Development Service dalam Pengembangan Usaha Kecil Menengah di Wedoro Centre Waru Sidoarjo," Jurnal Manajemen dan Kewirausahaan, vol. 10, no. 2, pp. 169-176, 2009.

[17] C. Pauwels, B. Clarysse, M. Wright, and J. Van Hove, "Understanding a new generation incubation model: The accelerator," Technovation, vol. 50, pp. 13-24, 2016.

[18] A. Bergek and C. Norrman, "Incubator best practice: A framework," Technovation, vol. 28, no. 1-2, pp. 20-28, 2008.

[19] Tanjung, B. M. R. P, Ed., ed, 2018.

[20] T. Andoria, B. M. R. P, Ed., ed, 2019.

[21] Z. Effendi, "Wali Kota Risma Ingin UKM Surabaya Lebih Kompetitif," in Detik.com, ed, 2018

[22] Dinas Koperasi UKM Jatim, "Jumlah UMKM dan Tenaga Kerja per sektor se-Jawa Timur.," 2013.

[23] M. Esmaelian, M. Tavana, D. Di Caprio, and R. Ansari, "A multiple correspondence analysis model for evaluating technology foresight methods," Technological Forecasting and Social Change, vol. 125, pp. 188-205, 2017

[24] A. Heiko, "Consensus measurement in Delphi studies: review and implications for future quality assurance," Technological forecasting and social change, vol. 79, no. 8, pp. 1525-1536, 2012.

[25] E. O. Brien and I. Hamburg, "Supporting sustainable strategies for SMEs through training, cooperation and mentoring," Higher education studies, vol. 4, no. 2, p. 61, 2014.

[26] C. Davies, "Formal mentorship and entrepreneurial learning: The case of a support programme in the Western Cape clothing sector," University of the Western cape, 2017.

[27] I. Hamburg, "Improving young entrepreneurship education and knowledge management in SMEs by mentors," World journal of education, vol. 4, no. 5, p. 51, 2014. 
[28] J. Audet and P. Couteret, "Coaching the entrepreneur: features and success factors," Journal of Small Business and Enterprise Development, vol. 19, no. 3, pp. 515-531, 2012.

[29] N. Lancer, D. Clutterbuck, and D. Megginson, Techniques for coaching and mentoring. Routledge, 2016.

[30] Management Mentors, "Coaching vs Mentoring," 2013.

[31] R. Barrett, "Small business learning through mentoring: evaluating a project," Education+ Training, vol. 48, no. 8/9, pp. 614-626, 2006.

[32] H. Håkansson and D. Ford, "How should companies interact in business networks?," Journal of business research, vol. 55, no. 2, pp. 133-139, 2002.

[33] P. Naudé, G. Zaefarian, Z. N. Tavani, S. Neghabi, and R. Zaefarian, "The influence of network effects on SME performance," Industrial Marketing Management, vol. 43, no. 4, pp. 630-641, 2014.

[34] S. Chetty and D. B. Holm, "Internationalisation of small to mediumsized manufacturing firms: a network approach," International business review, vol. 9, no. 1, pp. 77-93, 2000.

[35] F.-J. Lin and Y.-H. Lin, "The effect of network relationship on the performance of SMEs," Journal of Business Research, vol. 69, no. 5 , pp. 1780-1784, 2016.

[36] A. G. Farinda, Y. Kamarulzaman, A. Abdullah, and S. Z. Ahmad, "Building business networking: A proposed framework for Malaysian SMEs," International Review of Business Research Papers, vol. 5, no. 2, pp. 151-160, 2009.
[37] H.-J. Bullinger, K. Auernhammer, and A. Gomeringer*, "Managing innovation networks in the knowledge-driven economy," International Journal of Production Research, vol. 42, no. 17, pp. 3337-3353, 2004

[38] R. Nainggolan, "Gender, tingkat pendidikan dan lama usaha sebagai determinan penghasilan UMKM Kota Surabaya," KINERJA, vol. 20, no. 1, pp. 1-12, 2016.

[39] J. Maes, L. Sels, and F. Roodhooft, "Learning about small business profitability: the influence of management practices and ownermanager human capital," 2004.

[40] Statistic Brain Research Institute, "Start-up Business Failure Rate By Industry," 2015

[41] W. R. Adawiyah, "Faktor Penghambat Pertumbuhan Usaha Mikro Kecil Menengah (UMKM): Studi di Kabupaten Banyumas," Sustainable Competitive Advantage (SCA), vol. 1, no. 1, 2013.

[42] L. Guiso and R. Minetti, "The structure of multiple credit relationships: Evidence from US firms," Journal of Money, Credit and Banking, vol. 42, no. 6, pp. 1037-1071, 2010.

[43] J. Hartšenko and A. Sauga, "The role of financial support in SME and economic development in Estonia," Business \& Economic Horizons, vol. 9, no. 2, 2013.

[44] A. Eriksson, "Government Financing of SMEs: A case study of the Swedish business development check for internationalization," ed, 2017.

[45] E. Jeanne and P. D. Leedy, Practical Research: Planning and Design a Research, 8 ed. Ohio: Pearson Merrill Prentice Hall., 2005. 